\title{
A coordinated dispatch model for electricity and heat in a Microgrid via particle swarm optimization
}

Xu, Lizhong; Yang, Guangya; Xu, Zhao; Bao, Zhe Jing; Jiang, Quan Yuan; Cao, Yi Jia; Østergaard, Jacob

Published in:

Transactions of the Institute of Measurement and Control

Link to article, DOI:

$10.1177 / 0142331211409098$

Publication date:

2013

Document Version

Early version, also known as pre-print

Link back to DTU Orbit

Citation (APA):

Xu, L., Yang, G., Xu, Z., Bao, Z. J., Jiang, Q. Y., Cao, Y. J., \& Østergaard, J. (2013). A coordinated dispatch model for electricity and heat in a Microgrid via particle swarm optimization. Transactions of the Institute of Measurement and Control, 35(1), 44-55. https://doi.org/10.1177/0142331211409098

\section{General rights}

Copyright and moral rights for the publications made accessible in the public portal are retained by the authors and/or other copyright owners and it is a condition of accessing publications that users recognise and abide by the legal requirements associated with these rights.

- Users may download and print one copy of any publication from the public portal for the purpose of private study or research.

- You may not further distribute the material or use it for any profit-making activity or commercial gain

- You may freely distribute the URL identifying the publication in the public portal 


\section{Transactions of the Institute of Measurement and Control}

\section{A coordinated dispatch model for electricity and heat in a Microgrid via particle swarm optimization}

\begin{tabular}{|c|c|}
\hline Journal: & Transactions of the Institute of Measurement and Control \\
\hline Manuscript ID: & TIMC-10-0090 \\
\hline Manuscript Type: & Original Manuscript \\
\hline $\begin{array}{r}\text { Date Submitted by the } \\
\text { Author: }\end{array}$ & 27-Oct-2010 \\
\hline Complete List of Authors: & $\begin{array}{l}\text { Xu, Lizhong; Zhejiang University, Department of Electrical } \\
\text { Engineering } \\
\text { Yang, Guangya; Technical University of Denmark, Centre for } \\
\text { Electric Technology, Department of Electrical Engineering } \\
\text { Xu, Zhao; Hong Kong Polytechnic University, Department of } \\
\text { Electrical Engineering } \\
\text { Jiang, Quanyuan; Zhejiang University, Department of Electrical } \\
\text { Engineering } \\
\text { Cao, Yijia; Zhejiang University, Department of Electrical } \\
\text { Engineering } \\
\text { Østergaard, Jacob; Technical University of Denmark, Centre for } \\
\text { Electric Technology, Department of Electrical Engineering }\end{array}$ \\
\hline Keywords: & $\begin{array}{l}\text { optimization, Microgrid, Distributed Generation, intelligent } \\
\text { computing, combined heat and power, particle swarm optimization }\end{array}$ \\
\hline Abstract: & $\begin{array}{l}\text { This paper develops a coordinated electricity and heat dispatching } \\
\text { model for Microgrid under day-ahead environment. In addition to } \\
\text { operational constraints, network loss and physical limits are } \\
\text { addressed in this model, which are always ignored in previous } \\
\text { work. As an important component of Microgrid, detailed combined } \\
\text { heat and power (CHP) model is developed. The part load } \\
\text { performance of CHP is modeled by curve fitting method. } \\
\text { Furthermore, electric heater is introduced into the model to } \\
\text { improve the economy of Microgrid operation and enhance the } \\
\text { flexibility of the Microgrid by electricity-heat conversion. Particle } \\
\text { swarm optimization (PSO) is employed to solve this model for the } \\
\text { operation schedule to minimize the total operational cost of } \\
\text { Microgrid by coordinating the CHP, electric heater, boiler and heat } \\
\text { storage. The efficacy of the model and methodology is verified with } \\
\text { different operation scenarios. }\end{array}$ \\
\hline
\end{tabular}




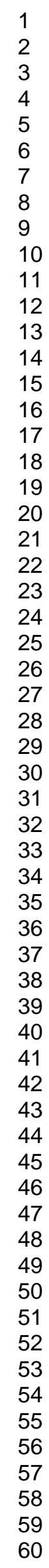

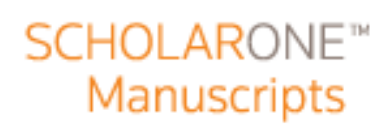

10

12

13

14

15

16

18

19

20

21

23

25

26

27

29

30

31

33

34

35

36

37

41

42

43

44

47

48

50

51

52

53

54

55

57

58

59

60

http://mc.manuscriptcentral.com/timc 
This paper develops a coordinated electricity and heat dispatching model for Microgrid under day-ahead environment. In addition to operational constraints, network loss and physical limits are addressed in this model, which are always ignored in previous work. As an important component of Microgrid, detailed combined heat and power (CHP) model is developed. The part load performance of CHP is modeled by curve fitting method. Furthermore, electric heater is introduced into the model to improve the economy of Microgrid operation and enhance the flexibility of the Microgrid by electricity-heat conversion. Particle swarm optimization (PSO) is employed to solve this model for the operation schedule to minimize the total operational cost of Microgrid by coordinating the CHP, electric heater, boiler and heat storage. The efficacy of the model and methodology is verified with different operation scenarios.

Keywords: Microgrid, distributed generation, combined heat and power, particle swarm optimization, optimal operation.

\section{Nomenclature}

$t \quad$ Index of hours

$n \quad$ Number in total (subscripts referring to corresponding items)

$c \quad$ Cost for per unit (subscripts referring to corresponding items)

$c M \quad$ Maintenance cost for per unit (subscripts referring to corresponding items)

$f_{C H P} \quad$ Electricity efficiency function of CHP associated to electricity output (?)

$\beta_{C H P} \quad$ Heat efficiency of CHP (\%)

$\eta_{B} \quad$ Boiler efficiency $(\%)$

$\eta_{E H} \quad$ Electric heater efficiency $(\%)$

$\eta_{T} \quad$ Hourly decay of heat storage (\%)

$\eta_{T I} \quad$ Charge efficiency of heat storage (\%)

$\eta_{T O} \quad$ Discharge efficiency of heat storage (\%)

$P_{C H P} \quad$ Active power output of CHP $(\mathrm{kW})$

$P_{C H P}^{\min }, P_{C H P}^{\max } \quad$ Power output limits of CHP $(\mathrm{kW})$

$R D_{C H P}, R U_{C H P}$ Ramping down and up limits of CHP $(\mathrm{kW})$

$P_{n D i s} \quad$ Power output from non-dispatchable generators $(\mathrm{kW})$

$H_{B} \quad$ Heat output of boiler $(\mathrm{kW})$

$H_{B}^{\max } \quad$ Heat output capacity of boiler $(\mathrm{kW})$

$H_{T} \quad$ Heat storage level of heat storage (kWh)

$H_{T}^{\max } \quad$ Heat storage capacity of heat storage $(\mathrm{kWh})$

$H_{T I}, H_{T O} \quad$ Heat charge and discharge rates from heat storage $(\mathrm{kW})$

$H_{T I}^{\max }, H_{T O}^{\max } \quad$ Heat charge and discharge rate limits of heat storage $(\mathrm{kW})$

$H_{T}^{0} \quad$ Initial heat storage level of heat storage $(\mathrm{kWh})$

$H_{D} \quad$ Heat demand $(\mathrm{kW})$

$P_{\text {Grid }} \quad$ Power exchange with the external distribution network (either positive or negative values, indicates purchasing and selling power to the grid, respectively) (kW)

$P_{\text {Grid }}^{\max } \quad$ Power exchange limit between the external distribution network and Microgrid (kW)

$P_{\text {loss }} \quad$ Power loss of Microgrid $(\mathrm{kW})$

$P_{E H} \quad$ Power consumption rate of electric heater $(\mathrm{kW})$

$P_{E H}^{\max } \quad$ Maximum power capacity of electric heater $(\mathrm{kW})$

$U_{i} \quad$ Voltage amplitude of bus $i$

$U_{i}^{\min }, U_{i}^{\max } \quad$ Voltage amplitude limits of bus $i$ 
$S_{i j}$ Apparent power flow from bus $i$ to bus $j$

$S_{i j}^{\max }$

Apparent power limit

\section{Introduction}

Distributed generations (DGs) have been applied rapidly due to its potential to significantly reduce emissions and ultimately the system operational cost (Pehnt 2006; Hatziargyriou, Asano et al. 2007). To utilize the benefits from the emerging potential of DGs, it is necessary to view the DGs and associated loads as a subsystem which is so-called "Microgrid" (Lasseter 2002). Microgrid comprises of low voltage distribution systems including distributed energy resources (DERs), storage devices and controllable loads, which are operated in a controlled and coordinated way to provide consumers the reliable and economic electricity and heat.

The operation of Microgrid offers distinct advantages to customers and utilities, i.e. improved energy efficiency, minimization of overall energy cost, reduced environmental impact, improvement of reliability and resilience, network operational benefits and more cost efficient electricity infrastructure replacement (Lasseter, R. H., A Akhil. et al. 2002) In most time, Microgrid is operated with the interconnection to the grid and is transmitted to island mode during fault conditions in external distribution network. Microgrid will be reconnected to external distribution network when fault is cleared.

There are two control strategies that have been proposed to Microgrid operation, decentralized control and hierarchical (centralized) control. In order to achieve the full benefits from the operation of Microgrid, it is important that all components work coordinately to achieve overall optimal operation of the whole system. To reach this goal, the hierarchical control is determined which contains three control levels (Katiraei, Iravani et al. 2008; Tsikalakis and Hatziargyriou 2008; Zhenhua and Dougal 2008), Distribution Management System (DMS), Microgrid Central Controller (MGCC), and Local Controllers (LC). Here, DMS is responsible to manage and control the distribution system in which may contain one or more Microgrids. MGCC is the interface between the DMS and the Microgrid, which can be dedicated to optimize the Microgrid operation or coordinate the local controllers. LC is employed to control DERs.

In (Lasseter, R. H., A Akhil. et al. 2002), potential research issues with Microgrid are proposed and discussed, including generation technologies, design and operation, protection, and economic problem. Research efforts have been carried out on economic problems (Celli, Pilo et al. 2005; Hernandez-Aramburo, Green et al. 2005; Awad, Chaudry et al. 2009; Hawkes and Leach 2009; Mashhour and MoghaddasTafreshi 2010). In (Awad, Chaudry et al. 2009), optimal power flow is employed for optimizing the operation of electric power networks whilst satisfying all network constraints, as well as operational constraints. But it is based on hourly optimal operation. In (Hernandez-Aramburo, Green et al. 2005), optimal Microgrid operation is performed in hourly based manner. A linear programming based cost minimization model using unit commitment of generators and storages is developed in (Hawkes and Leach 2009), where system physical constraints and operational limits are addressed and the optimal dispatch of electricity and heat of 24-hour is performed. However, the CHP efficiency is assumed to be constant which may not precise enough. In (Celli, Pilo et al. 2005), a novel Energy Management System (EMS) based on Neural Networks (NN) is developed, which can hourly dispatch generators with the goal of minimizing the energy costs. However, network loss and physical limits of Microgrid have not been considered in the study. A 24-hour optimization model of Microgrid is developed in (Mashhour and Moghaddas-Tafreshi 2010), where operational constraints, network loss and physical limits are included, while the electricity and heat are not coordinately dispatched in this model. 
Other than the previous work, in this paper, a coordinated dispatch model of electricity and heat is developed for Microgrid operation to minimize its operational cost under a day-ahead market environment, especially the network loss and physical limits are addressed, which may not be negligible in Microgrid operation (Mashhour and Moghaddas-Tafreshi 2010). CHP part load performance is strengthened and modeled by curve fitting method. The models of electric heater and storage are included into the Microgrid model and utilized to improve the flexibility and economy of Microgrid. The operational constraints include DGs ramping limits, storage charge/discharge rate limits, and DERs capability limits. The proposed optimization model is a nonlinear mixed-integer programming optimization problem which normally cannot be solved efficiently by conventional gradient-based methods. In this paper, particle swarm optimization (PSO) is exploited to solve this problem.

The paper is organized as follows. In Section II, the schematic diagram of Microgrid is provided which illustrates the proposed Microgrid model, followed by the depiction of the components. Also, the modeling of part load performance of CHP is detailed. In Section III, the day-ahead optimization model for Microgrid is formulated and described. The fundamentals of PSO are described in Section IV. Simulation results are provided and discussed in Section V considering different scenarios. Conclusion is drawn in Section VI.

\section{Microgrid Components and Operation}

Microgrid is operated as a combined producer and consumer, which is a consumer when imports electricity from external distribution network and is a producer when exports electricity to external distribution network. Microgrid may consist of dispatchable and/or non-dispatchable generators, and electrical and/or heat storages. The electrical components are linked by the low voltage network which connects to the external distribution system through Point of Common Connection (PCC) to import or export electricity.

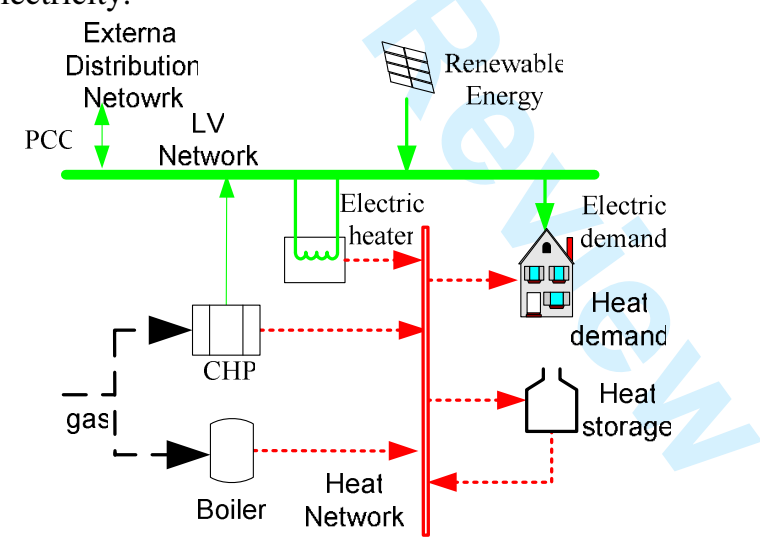

Figure 1 Schematic diagram typical Microgrid.

\subsection{Main Microgrid Components}

A schematic diagram of a typical Microgrid is shown in Figure 1. It consists of low voltage network with connection to the external distribution network, CHP, boiler, electric heater and heat storage.

\subsubsection{Distribution Network}

Microgrid is connected to the distribution network and exchanges electricity with distribution network bilaterally. Microgrid is operated mostly interconnected to the 
distribution network, but can also be operated disconnected from the main grid in the case of faults in the external distribution network.

\subsubsection{Combined Heat and Power}

As an important component, CHP generates electricity and provides recoverable heat simultaneously. Since the operation of CHP has contribution on both electricity and heat, its performance has big impact on the Microgrid economical operation. In the previous work, CHP is normally assumed to run at its maximum capacity which may not lead to the optimal economical operation of the whole system; and its efficiency is assumed to be constant for different load ratio, which is also not precise enough to reflect its performance. Here, part load model is considered and the performance is modeled by curve fitting method.

In this study, the micro CHP (CAPSTONE 2009) is taken as an example and its performance curve is shown in Figure 2. With the 3rd degree polynomial fitting function for the electricity efficiency curve, the parameters can be obtained as below.

$$
\eta_{C H P}=f\left(P_{e}\right)=\mathrm{p}_{1}\left(P_{e}\right)^{3}+\mathrm{p}_{2}\left(P_{e}\right)^{2}+\mathrm{p}_{3}\left(P_{e}\right)+\mathrm{p}_{4}
$$

Table 1 Efficiency curve fitting parameter

\begin{tabular}{llll}
\hline $\mathrm{p}_{1}$ & $\mathrm{p}_{2}$ & $\mathrm{p}_{3}$ & $\mathrm{p}_{4}$ \\
\hline $5.21 \mathrm{e}-08$ & $-2.53 \mathrm{e}-5$ & $4.18 \mathrm{e}-3$ & $9.26 \mathrm{e}-2$ \\
\hline
\end{tabular}

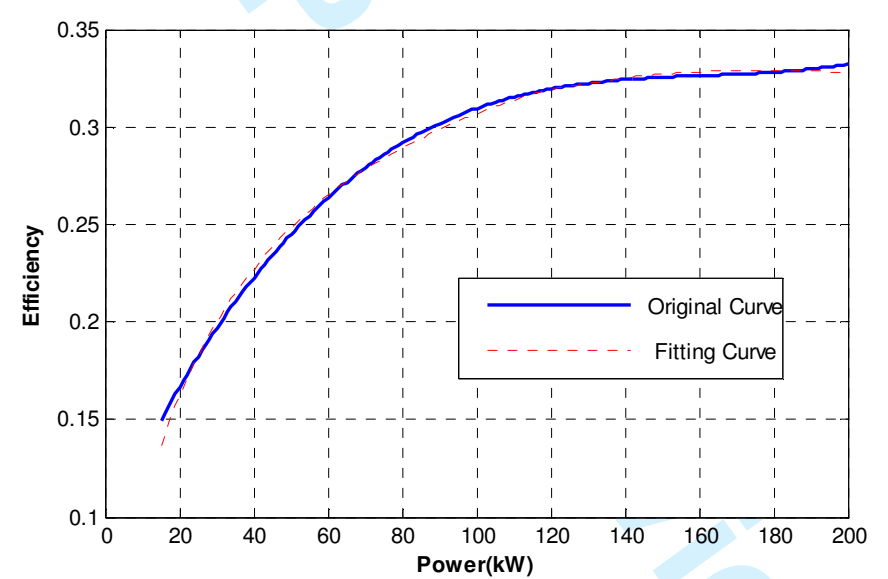

Figure 2 CHP part load efficiency.

From Figure 2, it can be seen that the efficiency of CHP is dependent on the power output level. If there is more than one CHP unit in the system, the efficiency of the CHP will be determined by the load distribution among the units. In this paper, it is assumed that there is more than one unit installed as one group in the system and the load is shared evenly among all the units. Figure 3 shows an example of the efficiency curve with $4 \mathrm{CHP}$ units. Due to the discrete nature of the curve, integer variables are introduced in the efficiency curve of equation (1) when group of CHPs are installed.

In this paper, the heat output is proportional to fuel rate of CHP at the efficiency of $50 \%$ (CAPSTONE 2009). As shown in Figure 2, the electricity efficiency is at the highest 0.33 , therefore the heat to power ratio (HPR) of CHP is above 1.6.

\subsubsection{Electric Heater and Heat Storage}

In this model, electric heater is used to convert electricity to heat which has a Coefficient of Performance (COP) of 0.98. In addition to CHP, electric heater is another component which links the electricity and heat in the Microgrid model.

Heat storage which stores energy in a heat reservoir is also considered in the Microgrid model to balance surplus heat supply. It can be used to improve the flexibility of Microgrid operation. 


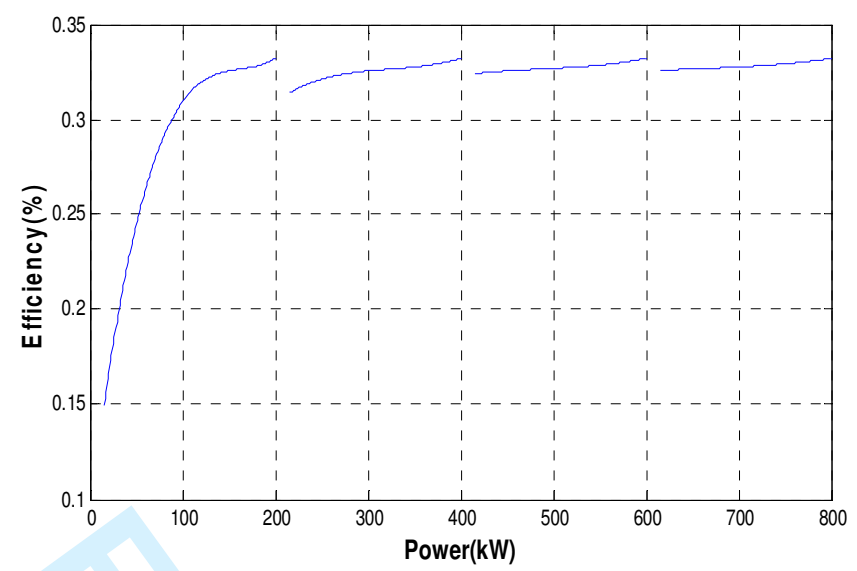

Figure 3 Group installed CHP (4 units) part load efficiency.

\subsection{Optimal Operation of Microgrid}

In operation, all controllable components, e.g. CHP, boiler, heat storage and electric heater, are dispatched coordinately to contribute to the optimal operation of Microgrid. As a non-dispatchable resource, the output of renewable energy is forecasted beforehand. Different electricity tariffs during the peak/off-peak time need to be considered in the optimization. Moreover, since the electricity peak demand is in the daytime, while the heat peak demand is normally in the night and morning, therefore, CHP may contribute to generate electricity in the daytime to cut the peak power demand, while electric heater can supply heat in the night and morning when the electricity tariff is low. Meanwhile, heat storage may aid CHP to store the surplus heat in the daytime when power demand is high while heat demand is low. With this arrangement, the overall operational cost of Microgrid could be optimized.

\section{Mathematical Modeling}

The objective function and the associated constraints of this problem are described as follows. In this paper, the optimization model is based on hourly interval for day-ahead scheduling.

\subsection{Objective Function}

The objective of optimal operation of Microgrid is to minimize the operational cost with respect to operational and physical constraints. The operational costs include electricity exchange cost with external distribution network, fuel cost of CHP and boiler, as well as maintenance cost (Siddiqui AS June 2003).

The objective function is presented as,

$$
\begin{aligned}
& O F=\sum_{t=1}^{24}\left(c_{\text {Grid }}^{t} P_{\text {Grid }}^{t}+c_{\text {Gas }} \sum_{i=1}^{n_{C H P}} f_{C H P i}\left(P_{C H P i}^{t}\right)+c_{G a s} \sum_{i=1}^{n_{B}} H_{B i}^{t} / \eta_{B i}\right. \\
& \left.\sum_{i=1}^{n_{C H P}} c M_{C H P i} P_{C H P i}^{t}+\sum_{i=1}^{n_{n D i s}} c M_{n D i s i} P_{n D i s i}^{t}+c M_{T}\left(H_{T I}^{t}+H_{T O}^{t}\right)+c M_{E H} P_{E H}^{t}\right)
\end{aligned}
$$

where the first item is electricity exchange cost with external distribution network; the second and third items are the fuel consumption costs of CHP and boiler, 
respectively; and the last four items are the maintenance costs which are proportional to the produced power by $\mathrm{CHP}$, renewable resources, charging and discharging of heat storage, and the consumption of electric heater, respectively.

\subsection{Constraints}

The constraints imposed on the optimization are energy balance, capacity and technical limits of components and physical limits of Microgrid, etc.

The electricity demand and supply balance constraints are expressed as

$$
P_{\text {Grid }}^{t}+\sum_{i=1}^{n_{C H P}} P_{C H P i}^{t}+\sum_{i=1}^{n_{n D i s}} P_{n D i s i}^{t}=P_{D}^{t}+P_{\text {loss }}^{t}+P_{E H}^{t}
$$

The lower and upper limits of CHP output, and CHP ramp down and up should also be satisfied.

$$
\begin{gathered}
P_{C H P i}^{\min } \leq P_{C H P i}^{t} \leq P_{C H P i}^{\max } \quad i \in n_{C H P} \\
R D_{C H P i} \leq P_{C H P i}^{t+1}-P_{C H P i}^{t} \leq R U_{C H P i} \quad i \in n_{C H P}
\end{gathered}
$$

The physical limits of Microgrid are

$$
\begin{gathered}
U_{i}^{\min } \leq U_{i}^{t} \leq U_{i}^{\max } \quad i \in n_{B U S} \\
S_{i j}^{t}<S_{i j}^{\max }, S_{j i}^{t}<S_{i j}^{\max } \quad i \in n_{B U S}, j \in n_{B U S}, i \neq j
\end{gathered}
$$

Power exchange with the main grid should be lower than the transformer or contracted capacity.

$$
\left|P_{\text {Grid }}^{t}\right| \leq P_{\text {Grid }}^{\max }
$$

The heat generation should be large equal than the heat demand.

$$
\sum_{i=1}^{n_{C H P}} H_{C H P i}^{t}+\sum_{i=1}^{n_{B}} H_{B i}^{t}+\eta_{E H} P_{E H}^{t}+\left(-H_{T I}^{t}+\eta_{T O} H_{T O}^{t}\right) \geq H_{D}^{t}
$$

Boiler output constraints are

$$
0 \leq H_{B i}^{t} \leq H_{B i}^{\max } \quad i \in n_{B}
$$

Electric heater operational constraints

$$
0 \leq P_{E H}^{t} \leq P_{E H}^{\max }
$$

The heat storage operational constraints, charging and discharging limits are expressed by

$$
\begin{gathered}
H_{T}^{t}=\left(1-\eta_{T}\right) H_{T}^{t-1}+\eta_{T I} H_{T I}^{t}-H_{T O}^{t} \\
0 \leq H_{T}^{t} \leq H_{T}^{\max } \\
0 \leq H_{T I}^{t} \leq H_{T I}^{\max } \\
0 \leq H_{T O}^{t} \leq H_{T O}^{\max }
\end{gathered}
$$

It is assumed that heat energy stored in the last hour heat storage finally is higher than the initial value. 


$$
H_{T}^{24} \geq H_{T}^{0}
$$

\section{Particle Swarm Optimization}

As mentioned before, the proposed model is a nonlinear mixed-integer programming optimization problem. As a recent member in EA family, particle swarm optimization (PSO) has been proven as an efficient solver in solving complex optimization problems. In this paper, the advances of PSO are exploited to optimize the operation of the proposed Microgrid model.

\subsection{Fundamentals of PSO}

The PSO algorithm was first proposed in 1995 by James Kennedy and Russell C. Eberhart (Kennedy and Eberhart 1995). PSO is a stochastic, population-based algorithm modeled on swarm intelligence. PSO consists of a population (or swarm) of particles, each of which represents a potential solution. Particles are assigned with random initial positions and fly through problem space with velocities to reach the global optimal solution. The fly velocity is influenced by both particle' $s$ own experience and the knowledge the particle acquires from the flock.

Given a problem dimension $n$, the particle position and velocity update equations in standard PSO are given by (Tang and Wu 2009; Zhu, He et al. 2009)

$$
\begin{gathered}
v_{i(d+1)}=w v_{i d}+c_{1} r_{1}\left(p_{i d}-x_{i d}\right)+c_{2} r_{2}\left(p_{g d}-x_{i d}\right) \\
x_{i(d+1)}=x_{i d}+v_{i d}
\end{gathered}
$$

where $i$ is the index of particle, $d$ is current generation, $r_{1}$ and $r_{2}$ are two uniform random numbers between 0 and 1. $c_{1}$ and $c_{2}$ are acceleration constants, and $w$ is coefficient of inertia weight. $p_{i d}$ and $p_{g d}$ are the particle's position with the best fitness value in current generation $d$, and the position with best fitness value achieved so far, respectively. The pseudo code for the PSO is given as follows: 


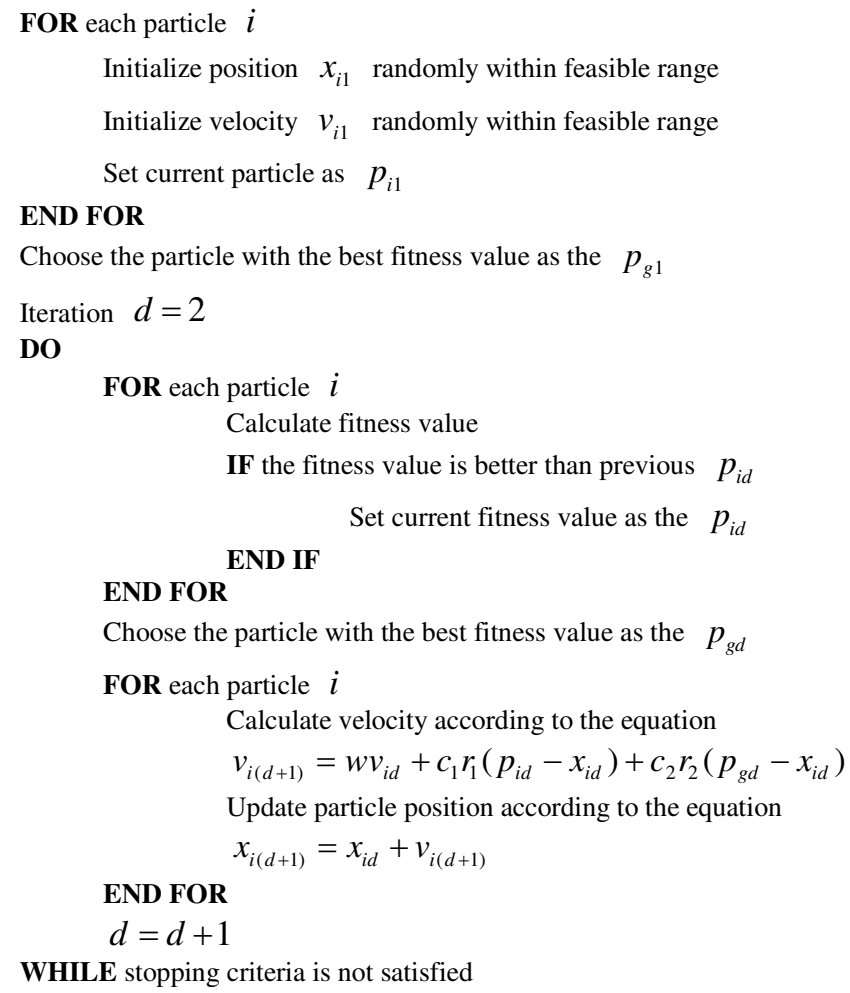

\section{END FOR}

\subsection{Implementation}

During the implementation of PSO, several techniques are used in this paper. First, the inertia weight $w$ is decreasing with the iterative generations as

$$
w=w_{\max }-\left(w_{\max }-w_{\min }\right) \frac{g}{G}
$$

where $g$ is the generation index representing the current generation number, and $G$ is a predefined maximum generation number. The maximum and minimum weights $w_{\max }$ and $w_{\min }$ are usually set to 0.9 and 0.4 , respectively (Zhi-Hui, Jun et al. 2009).

Additionally, in order to improve the searching ability of particle swarm, a velocity update strategy is exploited in this paper. When the best fitness does not change for a certain number of generations, position of neighborhood particle is used to update the velocity (Zheng 2010), which is formulated as

$$
v_{i(d+1)}=w v_{i d}+c_{1} r_{1}\left(\text { pbest }_{i}-x_{(i-1) d}\right)+c_{2} r_{2}\left(\text { gbest }-x_{(i-1) d}\right)
$$

With these advances, the algorithm is improved from the standard PSO from both prematurity prevention and local searching capability. 


\section{Case Studies}

\subsection{Test System}

In this section, a test Microgrid is employed to verify the proposed model and method (Kersting 1991). As shown in Figure 4, the model consists of two CHPs at node 709 and 720 with rated power capacity of $800 \mathrm{~kW}$ and $1000 \mathrm{~kW}$ respectively, one electric heater at node 709 , one solar panel at node 702 , one boiler, and one heat storage. Detail data is given in Table 2 .

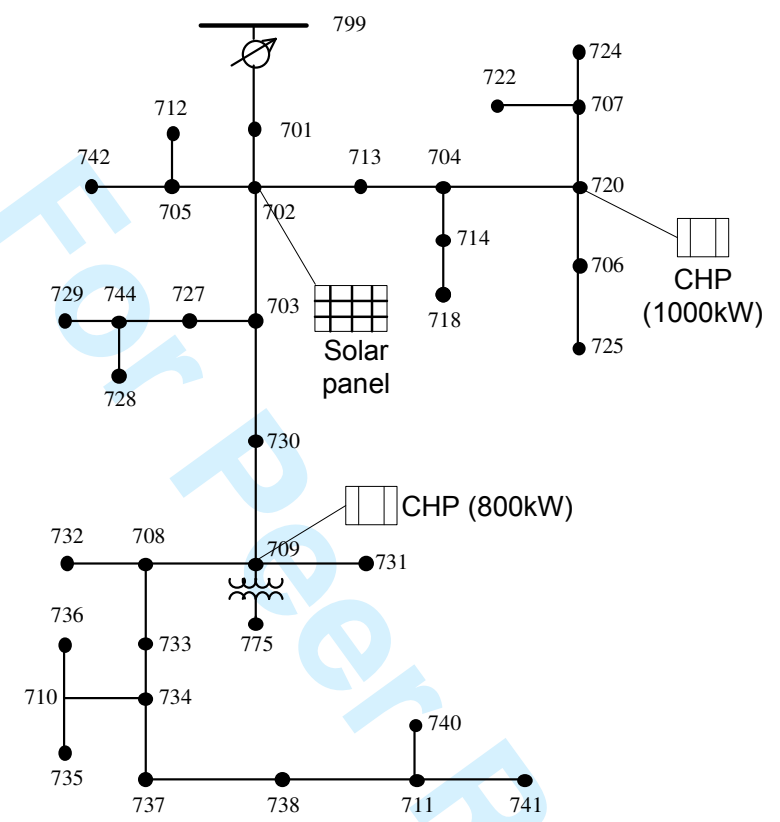

Figure 4 Single line diagram of the test Microgrid.

Table 2 System components data

\begin{tabular}{ccccc}
\hline Components & Capacity(kW) & \multicolumn{3}{c}{ Efficiency } \\
\hline Boiler & 2000 & 0.8 & \\
Electric Heater & 500 & 0.98 & \\
Heat Storage & 1000 & 0.98 & 0.9 & 1 \\
\hline
\end{tabular}

* Efficiency parameters for heat storage are decay, charging and discharging efficiencies, respectively.

In this paper, demand and solar panel output profiles are assumed to be accurately forecasted beforehand. The electricity and heat demand profiles refer to the data of a hotel. Figure 5 shows the profiles in January and July. 


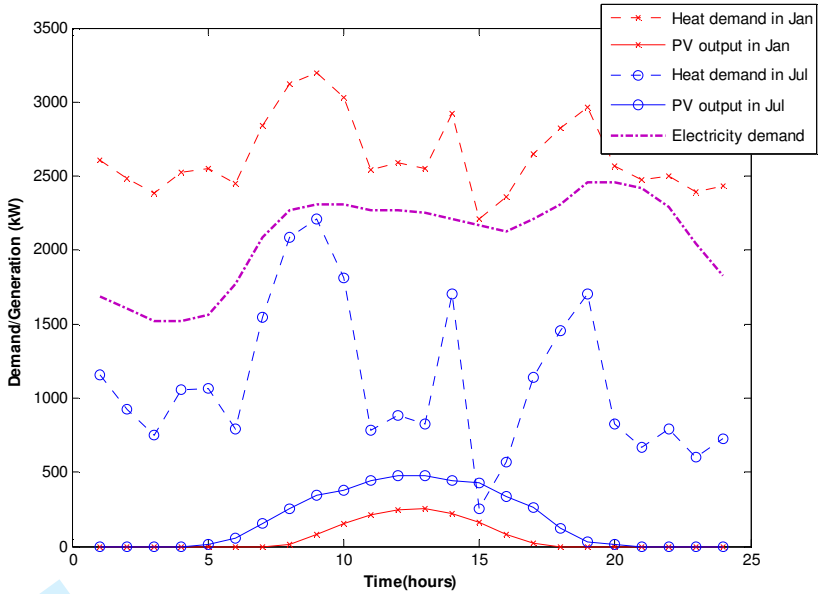

Figure 5 Electricity and heat load profiles for a hotel.

The operational cost is critically determined by fuel and electricity costs. The electricity tariff is given as time-of-use tariff, which is acquired from a utility. Twoperiod time-of-use tariff is adopted in this paper, which means that customer is charged at peak tariff $(0.668 \mathrm{RMB} / \mathrm{kWh})$ for any electricity consumed during hours 8 22 , and an off-peak tariff $(0.288 \mathrm{RMB} / \mathrm{kWh})$ during hours $23-7$. In the case study, a day-ahead 24 hours optimal scheduling of CHPs, electric heater, boiler and heat storage is implemented. Typical scenarios are selected based on the demands in different seasons and prices in a year. Different cases are tested as below and the results are presented. Case 1 and Case 2 are for winter day and summer day, respectively. In Case 3, gas tariff is assumed to be $0.15 \mathrm{RMB} / \mathrm{kWh}$ to evaluate the impact of gas tariff on the optimal operation. Energy tariff and maintenance costs are given in Tables 3 and 4.

Table 3 Energy tariff

\begin{tabular}{c|cc}
\hline \multirow{2}{*}{ Electricity } & Off-peak time $(1 \mathrm{~h}-7 \mathrm{~h}, 23 \mathrm{~h}-24 \mathrm{~h})$ & Peak time $(8 \mathrm{~h}-22 \mathrm{~h})$ \\
\cline { 2 - 3 } & $0.288 \mathrm{RMB} / \mathrm{kWh}$ & $0.668 \mathrm{RMB} / \mathrm{kWh}$ \\
\hline \multirow{2}{*}{ Gas } & Case 1,2 & Case 3 \\
\cline { 2 - 3 } & $0.35 \mathrm{RMB} / \mathrm{kWh}$ & $0.15 \mathrm{RMB} / \mathrm{kWh}$ \\
\hline
\end{tabular}

Table 4 Maintenance cost

\begin{tabular}{cc}
\hline Components & Maintenance $\operatorname{cost}(\mathrm{RMB} / \mathrm{kWh})$ \\
\hline CHP & 0.010 \\
Boiler & 0.005 \\
Electric heater & 0.005 \\
Heat storage & 0.005 \\
Solar panel & 0 \\
\hline
\end{tabular}

\subsection{Simulation Result}

\subsubsection{Case 1: winter day}

Simulation results are illustrated in Figure 6, 7. In Figure 6, the power output of CHPs, power exchange with the external distribution network, and the power consumption of electric heater are shown. It is observed that during hour 1-7 and hour 23-24 when electricity tariff is low, electric heater reaches almost its maximum capacity, while CHPs are running at lower output level. However, during hour 8-22 when electricity tariff is high, CHPs reach their upper levels, while electric heater is off. The power exchange curve shows that demand of peak hours is shifted to offpeak hours. 
Figure 7 shows the heat outputs of CHPs and boiler and consumption rate of electric heater. It can be seen that when CHPs are running at low output level, heat demand is balanced by electric heater and boiler. In the daytime when CHPs reach their upper limits, heat demand is balanced by the cooperation of CHPs and heat storage.

From the results, it can be seen that CHPs keep running at their maximum capacity during peak hours. This could be related to the heat to power demand ratio used in this case, which is around 1.3 close to the CHP HPR 1.6, as mentioned in Section II. This point will be further studied in Case 2.

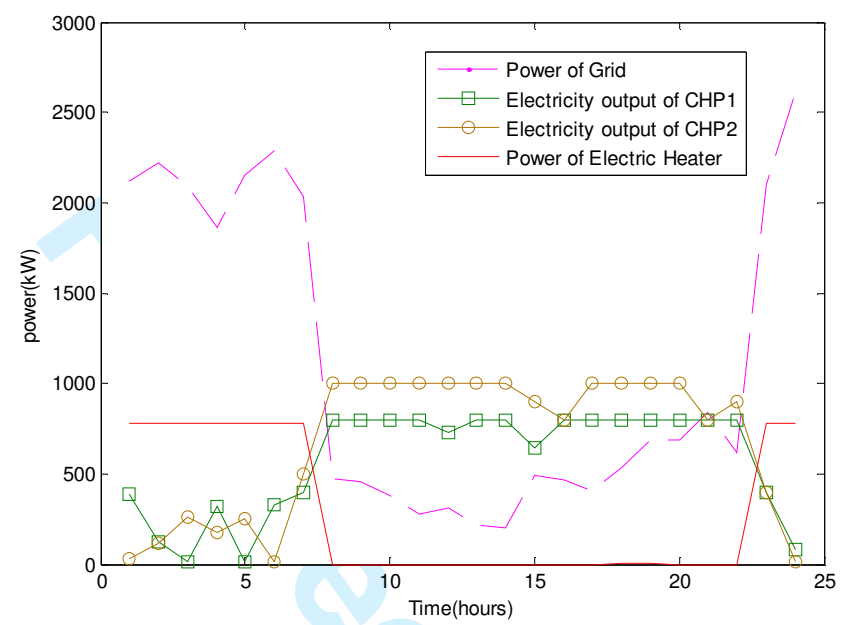

Figure 6 Electricity power output of the main components for winter day.

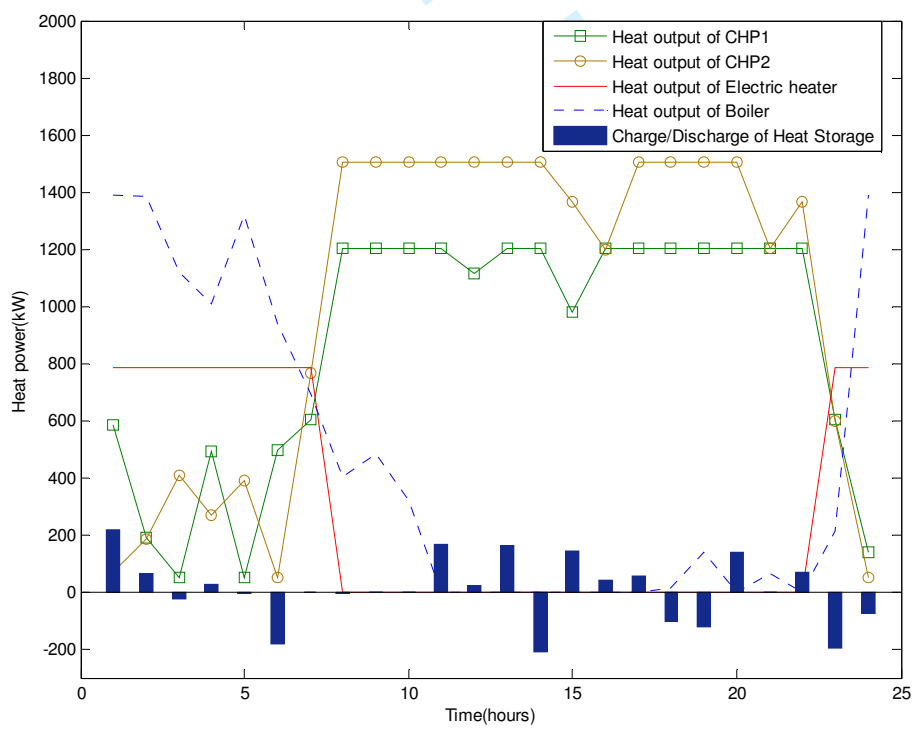

Figure 7 Heat output of the main components for winter day.

\subsubsection{Case 2: summer day}

Comparing to Case 1, Case 2 has lower heat demand while the electricity demand is the same. In Case 2, since it is in summer, the heat demand is lower than electricity demand, which means that heat demand to power demand ratio is smaller than 1.0. In this case, the heat to power demand ratio equals to 0.9 , which is much smaller than that of CHP (at least 1.6).

Simulation results are given in Figure 8 and 9. In Figure 8, it is obvious that the output of CHPs changes frequently. According to Figure 3, a group of CHPs achieve 
highest efficiency at the multiple of 200 (capacity of one unit CHP), hence CHPs always run at these points. Since HPR of demand is much lower than that of CHP, excess heat generated by CHP will be stored by heat storage for subsequent hours. Take hours 9-11 as example. At hour 9, power output of CHP1 and CHP2 are 600kW and $1000 \mathrm{~kW}$, respectively, and heat storage is charging with the extra heat. At hour 10 , power outputs of CHPs decrease, while power balance is kept by purchasing electricity from distribution network. At hour 11, power outputs of CHPs decrease further, while the power purchased from distribution network increases again to keep power balance. At the same time, heat storage discharges to provide heat to keep heat balance. It is also clear that electric heater is trying to run close to the maximum capacity when electricity tariff is low.

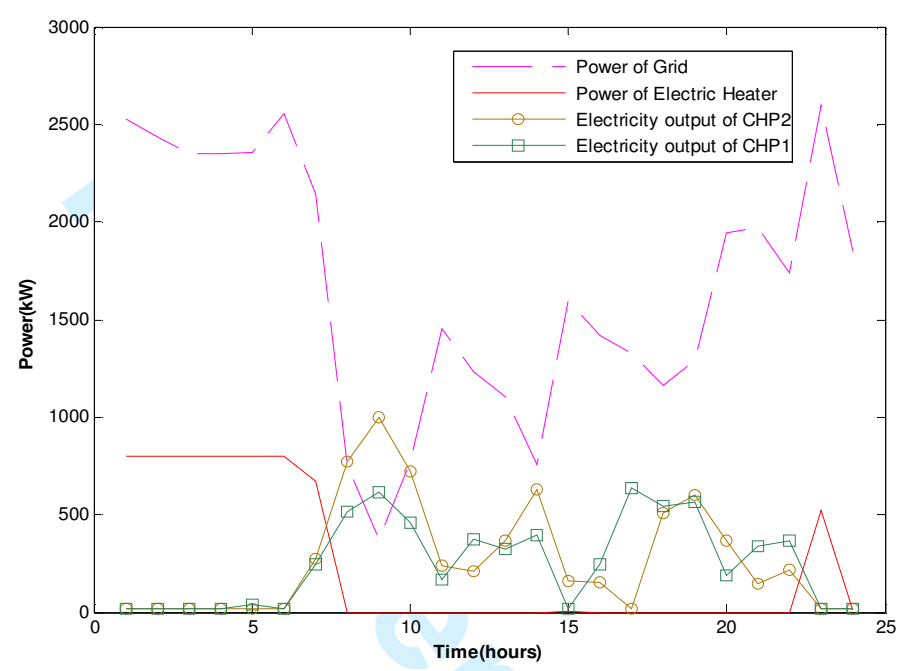

Figure 8 Electricity power output of the main components for summer day.

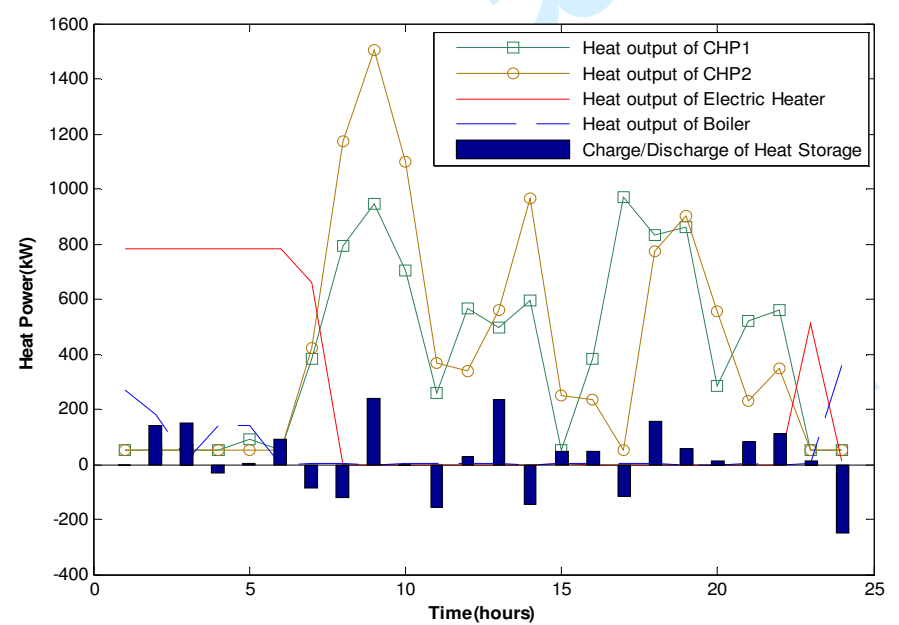

Figure 9 Heat output of the main components for summer day.

\subsubsection{Case 3: winter day with low gas tariff}

In this case, gas tariff is assumed to be $0.15 \mathrm{RMB} / \mathrm{kWh}$ (about $1.5 \mathrm{RMB} / \mathrm{m}^{3}$ ). It is obvious that electric heater is off all the day, as shown in Figure 10. Even at off-peak hours the heat supplied by boiler is cheaper than the electric heater. From Figure 10 and Figure 11, it is clear that CHPs are running at their maximum capacity, and boiler is employed only during hours 7-10 in the morning when heat demand cannot be 
satisfied only by CHPs. As shown in Figure 10, electricity is exported to external distribution network even during off-peak demand hours 1-6.

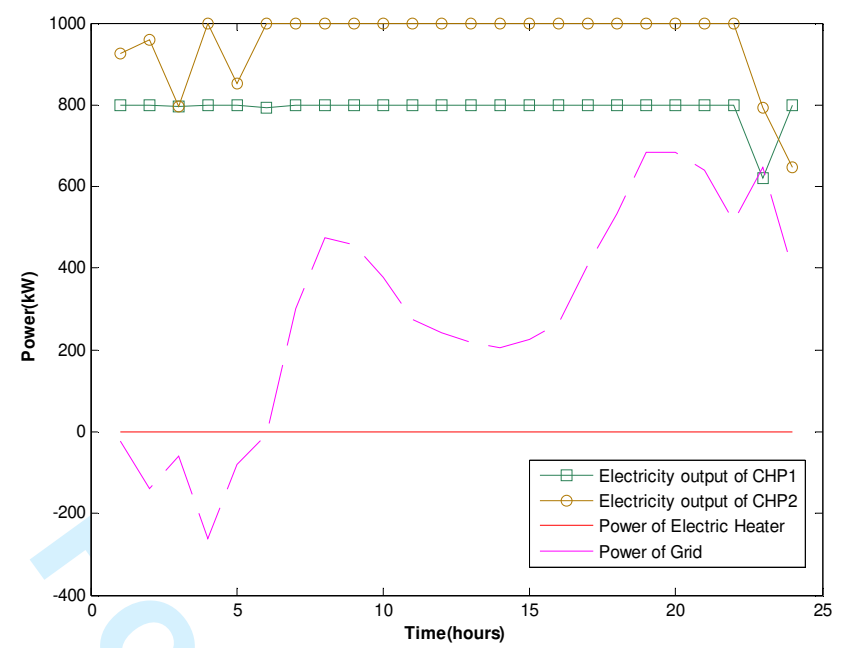

Figure 10 Electricity power output of the main components with reduced gas tariff for winter day.

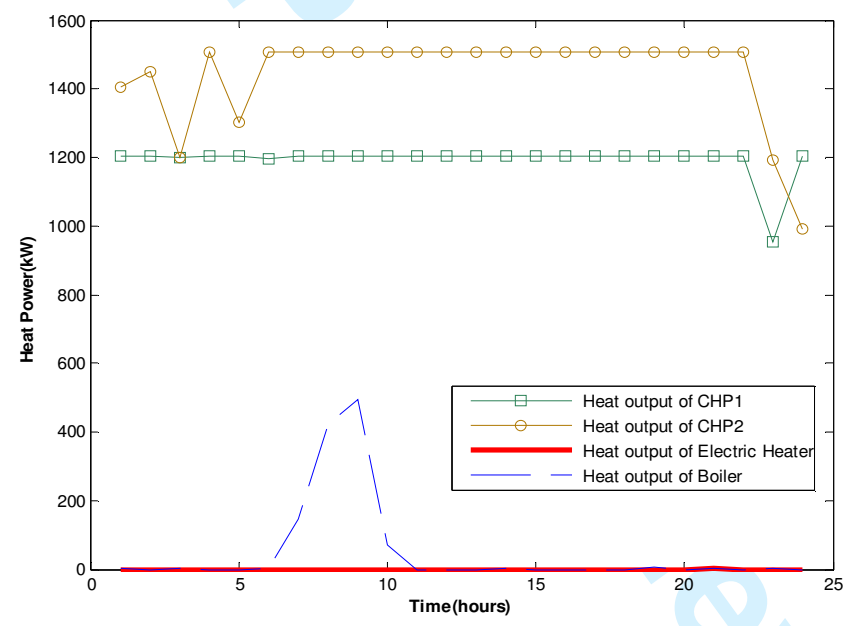

Figure 11 Heat output of the main components with reduced gas tariff for winter day.

\section{Conclusion}

In this paper, a Microgrid coordinated electricity-heat dispatch model is proposed and the operation is optimized via particle swarm optimization. The objective is to minimize the Microgrid operational cost, which includes the electricity exchange cost with the external distribution network, fuel cost of components, as well as the maintenance cost. Detailed CHP performance model is employed. Moreover, this model considers the physical limits and the loss of the grid which is not generally considered in the previous studies. The model is applied to a test Microgrid and results are analyzed under different cases.

It is found that the heat to power ratio (HPR) of demand has big impact on the optimal operation schedule. If the HPR of demand is close to the HPR of CHP, the CHPs would be on full power output during peak time, otherwise the output of CHPs changes frequently, which may influence the CHP's life-time. Cases with different 
gas tariffs show that with low gas tariff, CHP will have the highest priority in dispatching, while the electric heater has the lowest priority.

Future work will focus on including more constraints into account, such as unit start-up and shut-down limits, system reserves, reactive power, etc. The consideration on the influence of intermittence of renewable energy on the operation of Microgrid is another direction for the future research.

\section{Acknowledgement}

This work was supported in part by National High-tech R\&D Program of China (2009AA05Z221), Program for New Century Excellent Talents in University (Grant No. NCET-08-0489), Science and Technology Planning Project of Zhejiang Province, China (2009C34013), and Hong Kong Polytechnic University grants (\#ZZ7Q and \#ZV3E).

\section{References}

Awad, B., M. Chaudry, et al. (2009). Integrated optimal power flow for electric power and heat in a MicroGrid. Electricity Distribution - Part 1, 2009. CIRED 2009. 20th International Conference and Exhibition on Electricity Distribution - Part 1, 2009.

CAPSTONE. 2009: CAPSTONE C200 MICROTURBINE TECHNICAL REFERENCE.

Celli, G., F. Pilo, et al. 2005: Optimal participation of a microgrid to the energy market with an intelligent EMS. The 7th International Power Engineering Conference, 2005.

Hatziargyriou, N., H. Asano, et al. 2007: Microgrids: an overview of ongoing research, development and demonstration projects. IEEE Power and Energy Magazine, 5(4): 78-94.

Hawkes, A. D. and M. A. Leach. 2009: Modelling high level system design and unit commitment for a microgrid. Applied Energy, 86(7-8): 1253-1265.

Hernandez-Aramburo, C. A., T. C. Green, et al. 2005: Fuel consumption minimization of a microgrid. IEEE Transactions on Industry Applications, 41(3): 673-681.

Katiraei, F., R. Iravani, et al. 2008: Microgrids management. IEEE Power and Energy Magazine, 6(3): 54-65.

Kennedy, J. and R. Eberhart. 1995: Particle swarm optimization. Proceedings of IEEE International Conference on Neural Networks, 1995.

Kersting, W. H. 1991: Radial distribution test feeders. IEEE Transactions on Power Systems, 6(3): 975-985.

Lasseter, R. H. 2002: MicroGrids. IEEE Power Engineering Society Winter Meeting, 2002.
Lasseter, R. H., A Akhil. et al. 2002: The CERTS Microgrid Concept. White paper for Transmission Reliability Program, Office of Power Technologies, U.S. Department of Energy.

Mashhour, E. and S. M. MoghaddasTafreshi. 2010: Integration of distributed energy resources into low voltage grid: A market-based multiperiod optimization model. Electric Power Systems Research, 80(4): 473-480.

Pehnt, M., Cames, M., Fischer, C., Praetorius, B. et al. 2006: Micro Cogeneration: Towards Decentralized Energy Systems. Berlin, Springer.

Siddiqui AS, F. R., Ghosh S, et al. 2003: Distributed energy resources with combined heat and power applications, Ernest Orlando Lawrence Berkeley National Laboratory.

Tang, W. J. and Q. H. Wu. 2009: Biologically inspired optimization: a review. Transactions of the Institute of Measurement and Control, 31(6): 495515.

Tsikalakis, A. G. and N. D. Hatziargyriou. 2008: Centralized Control for Optimizing Microgrids Operation. IEEE Transactions on Energy Conversion, 23(1): 241-248.

Zheng, X. 2010: Research on Dynamic Modeling and Intelligent Algorithm of Power System Energy-saving Generation Dispatch with Wind Farms Embedded, Zhejiang University. MS.

Zhenhua, J. and R. A. Dougal. 2008: Hierarchical microgrid paradigm for integration of distributed energy resources. IEEE Power and Energy Society General Meeting - Conversion 
and Delivery of Electrical Energy in the 21st Century, 2008.

Zhi-Hui, Z., Z. Jun, et al. 2009: Adaptive Particle Swarm Optimization. IEEE Transactions on Systems, Man, and Cybernetics, Part B: Cybernetics, 39(6): 1362-1381.
Zhu, Y. L., X. X. He, et al. 2009: Information entropy based interaction model and optimization method for swarm intelligence. Transactions of the Institute of Measurement and Control, 31(6): 461-474. 